\title{
The anti-leukemic effect and molecular mechanisms of novel hydroxamate and benzamide histone deacetylase inhibitors with 5-aza-cytidine
}

\author{
H.B. LIU ${ }^{1,2}$, P.A. MAYES ${ }^{3}$, P. PERLMUTTER ${ }^{3}$, J.J. McKENDRICK ${ }^{4}$ and A.E. DEAR ${ }^{1,2}$ \\ ${ }^{1}$ Australian Centre for Blood Diseases, ${ }^{2}$ Biotechnology Division: Eastern Clinical Research Unit, \\ Monash University, 6th Floor Burnett Tower, 89 Commercial Road, Prahran 3181, Melbourne; \\ ${ }^{3}$ Department of Chemistry, Monash University, Clayton 3168; ${ }^{4}$ Box Hill Hospital Department of Oncology, \\ Box Hill Hospital, Nelson Road, Box Hill 3128, Melbourne, Victoria, Australia
}

Received October 15, 2010; Accepted November 26, 2010

DOI: $10.3892 /$ ijo.2011.914

\begin{abstract}
Histone deacetylase inhibitors (HDACi) demonstrate considerable in vitro and in vivo activity and clinical efficacy in the treatment of hematological malignancies. Pre-clinical and early phase clinical trials identify therapeutic activity using a combination of HDACi and demethylating agents which may be more efficacious than single agent treatment. Our studies aimed to determine the effects and molecular mechanisms of action of novel hydroxamate (MCT-3) and benzamide [MGCD0103 (MG)] HDACi's in the HL-60 cell line alone and in combination with the demethylating agent 5-aza-cytidine (AZA). MG, MCT-3 and AZA treatment significantly inhibited HL-60 cell growth in vitro with MG being the most potent agent. MG in combination with AZA demonstrated no significant increase in inhibition of cell growth over MG treatment alone whilst MCT-3 in combination with AZA demonstrated increased inhibition of cell growth over either agent alone although no more significant than MG alone. MG alone or MCT-3 in combination with AZA significantly increased $\mathrm{p} 15$ and caspase- 3 expression. MG and MCT-3 significantly attenuated AZA-induced MMP-9 mRNA expression and proteolytic activity. Interestingly, MCT-3, MG and AZA alone and in combination increased expression of the novel tumour suppressor gene Nur77, important in leukemogenesis, with MG a more potent inducer as a single agent. These observations suggest the enhanced anti-leukemia activity of the combination of AZA and HDACi may only reside with certain HDACi classes and may be in-part explained by regulation of genes associated with cell cycle arrest, apoptosis and tumour suppression.
\end{abstract}

Correspondence to: Dr A.E. Dear, Australian Centre for Blood Diseases, Monash University, 6th Floor Burnett Tower, 89 Commercial Road, Prahran 3181, Melbourne, Victoria, Australia E-mail: anthony.dear@monash.edu

Key words: HDACi, hydroxamate, benzamide, demethylation

\section{Introduction}

Histone deacetylase inhibitors (HDACi) represent a novel, structurally heterogeneous class of compounds. The four chemical classes of HDACi, include the benzamides (e.g., MGCD0103), the hydroxamates (e.g., MCT-3, SAHA), the short-chain fatty acids (e.g., valproic acid), and the cyclic tetrapeptides (e.g., Depsipeptide/FK228) (1-4). The hydroxamates are frequently referred to as 'broad-spectrum' or 'pan'-HDACi resulting from inhibition of several HDAC isoforms). The remaining chemical classes of $\mathrm{HDACi}$ selectively inhibit class I HDACs $(3,4)$.

HDACi have recently been described to have significant therapeutic activity in the treatment of hematological malignancies including cutaneous T-cell lymphoma, Hodgkin's lymphoma, myelodysplastic syndrome (MDS) and acute myeloid leukemia (AML) (5). In vitro $\mathrm{HDACi}$ have been shown to up-regulate the expression of $\mathrm{p} 15^{\mathrm{INK} 4 \mathrm{~b}}, \mathrm{p} 21^{\mathrm{WAF} / \mathrm{CIP} 1}$, caspase-3 and the inducible orphan nuclear receptor Nur-77, whose expression is important in the induction of apoptosis and has recently been demonstrated to be abrogated in acute myeloid leukemia, whilst also down regulating Bcl-XL and MMPs in cell lines (6-14).

Numerous in vitro studies together with recent pre-clinical and early phase clinical studies identify significant antileukemic activity of a combination of HDACi with demethylating agents with greater inhibition of growth and DNA synthesis, and a greater loss of clonogenicity than that observed by single agent treatment in in vitro studies (14-20). However, the mechanisms of HDACi-induced cell death and underlying the anti-cancer synergy between HDACi and other agents are not completely understood. As a consequence of the complexity of the cellular actions of HDACi, it is currently unclear as to whether pan-HDACi or specific HDACi will provide the most clinical benefit to patients when used in combination with demethylating agents (1).

MGCD0103, an orally available class I benzamide HDACi, has been reported to have broad spectrum anti-tumour activity in vitro and anti-leukemia activity in a phase I study $(21,22)$. Based on the known hypomethylating activity and clinical 
anti-leukemia activity of AZA and the reported HDACi activity of MGCD0103, we studied the effect of these agents alone or in combination and compared them with a novel hydroxamate HDACi, MCT-3 (4), in the HL-60 leukemia cell line and explored the molecular mechanisms responsible for these effects.

\section{Materials and methods}

Cell culture. HL-60 cells were cultured in RPMI-1640 (Gibco BRL) containing $10 \%$ heat inactivated fetal calf serum and kept in a $5 \% \mathrm{CO}_{2}$ incubator at $37^{\circ} \mathrm{C}$. Agents: AZA (kind gift of Celgene Pty Ltd., Australia), MG (kind gift of MethylGene, Pty Ltd., Quebec, Canada) and MCT-3, (synthesized as a meta-substituted biphenyl analogue of Oxamflatin in the Department of Chemistry, Monash University, Melbourne, Victoria, Australia $(4,23)$ were added to plates for $24 \mathrm{~h}$. AZA was dissolved in $1 \%$ DMSO and used at a final concentration of $1.0 \mu \mathrm{M}$. MCT-3 and MG were dissolved in PBS with $1 \%$ DMSO and used at a final concentration of $0.5 \mu \mathrm{M}$.

Growth inhibition assay. HL-60 cells in log phase were plated at a density of $0.2 \times 10^{6}$ in $10 \mathrm{ml}$ of medium. Cells were harvested at $24 \mathrm{~h}$. Cell viability was assessed using $0.4 \%$ trypan-blue staining immediately after culture. Black staining cells were considered as non-viable cells, and unstained bright cells as viable. All experiments were repeated 3 times with averages displayed graphically.

Semi-quantatitive RT-PCR and real-time PCR. RT-PCR was performed on total RNA extracted from HL-60 cells. The primers used for $\mathrm{p} 15^{\mathrm{INK} 4 \mathrm{~b}}, \mathrm{p} 21^{\mathrm{WAF} 1 / \mathrm{CIP} 1}$, caspase-3, MMP-9 and the human GAPDH gene were prevously described (14). All PCR products were sequenced to confirm the identities and repeated 3 times.

Scanning densitometry analyses were performed on RTPCR products using the GeneSnap imaging software (Synoptics, UK). Band intensity values for $\mathrm{p} 15^{\mathrm{INK} 4 \mathrm{~b}}, \mathrm{p} 21^{\mathrm{WAF} 1 / \mathrm{CIP} 1}$, caspase-3 and MMP-9 mRNA were normalized to those for GAPDH mRNA and the resultant $\mathrm{p} 15^{\mathrm{INK} 4 \mathrm{~b}}, \mathrm{p} 21^{\mathrm{WAF} 1 / \mathrm{CIP} 1}$, caspase-3 and MMP-9: GAPDH ratios were plotted to illustrate variations in gene expression.

Real-time PCR was performed as previously described (14). The primers for $\beta$-actin: 5'-GAC AGG ATG CAG AAG GAG ATT ACT-3' and 5'-TGA TCC ACA TCT GCT GGA AGG T-3'. Forward and reverse primers for Nur-77: 5'-GCT GCA GAA TGA CTC CAC C-3' and 5'-ACA GCA GCA CTG GGC TTA-3'. Data were normalized to $B$-actin and presented as the mean fold change compared with control.

SDS-PAGE and zymography studies. An aliquot of conditioned medium from HL-60 cells treated with AZA or/and MCT-3 or MG, together with untreated control cells, was electro-phoresed through a $10 \%$ acrylamide SDS-PAGE gel containing $0.15 \%$ gelatin under non-denaturing conditions. Gels were washed and incubated in developing buffer at $37^{\circ} \mathrm{C}$ overnight. The gels were stained with Coomassie blue R250 and destained with water. A SDS-PAGE gel (without gelatin) was used as a loading control. All experiments were repeated 3 times.
A

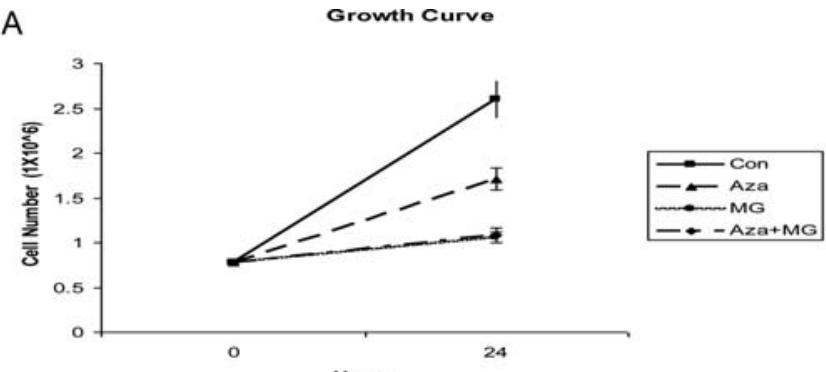

B

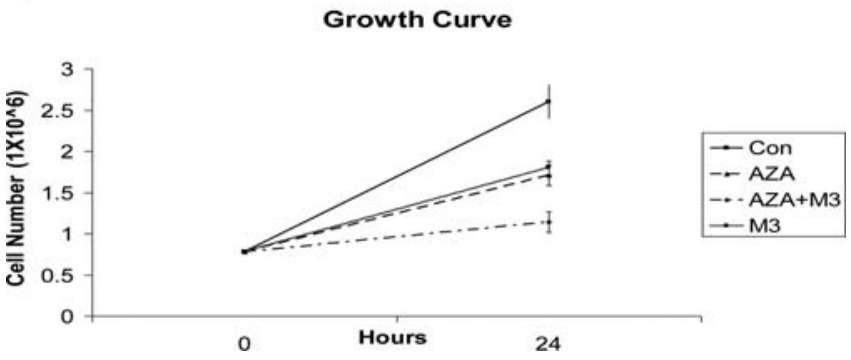

Figure 1. Effect of MG (A) or MCT-3 (B) alone and in combination with AZA on HL-60 cell growth. Numbers on the Y-axis represent the total number of viable cells at $24 \mathrm{~h}$. Con, HL-60 cells without treatment; AZA, cells treated with $1.0 \mu \mathrm{M} 5$-aza-cytidine; M3, cells treated with $0.5 \mu \mathrm{M}$ MCT-3; MA, cells treated with $0.5 \mu \mathrm{M}$ MCT-3 $+1.0 \mu \mathrm{M}$ AZA; MG, cells treated with $0.5 \mu \mathrm{M}$ MGCD0103; MGA, cells treated with $0.5 \mu \mathrm{M}$ MGCD0103 + $1.0 \mu \mathrm{M}$ AZA.

Statistical methods. The effects of AZA, MCT-3, and MG alone and in combination on HL-60 cell growth, p15 ${ }^{\text {INK4b }}$, p21 $1^{\mathrm{WAF} 1 / \mathrm{CIP} 1}$, caspase-3 and MMP-9 expression were assessed by analysis of variance (ANOVA). Data were expressed as means \pm SEM and ${ }^{*} \mathrm{P}<0.05$ was considered statistically significant.

\section{Results}

MG, MCT-3 and AZA inhibit HL-60 cell growth. We examined the effects of MG (Fig. 1A) and MCT-3 (Fig. 1B) alone and in combination with AZA on the growth of the human leukemia cell line HL-60. Cells were exposed to MG $(0.5 \mu \mathrm{M})$, MCT-3 $(0.5 \mu \mathrm{M})$ and/or AZA $(1.0 \mu \mathrm{M})$ for up to $24 \mathrm{~h}$. These doses were selected as they induced growth inhibition in previous in vitro studies $(14,21)$. MG, MCT-3 and AZA treatment significantly inhibited HL-60 cell growth in vitro with MG being the most potent agent. MG in combination with AZA demonstrated no significant increase in inhibition of cell growth over MG treatment alone whilst MCT-3 in combination with AZA inhibited cell growth more effectively than either agent alone although no more effectively than MG alone (Fig. 1).

Effect of MG, MCT-3 and/or AZA on the expression of p15 $15^{I N K 4 b}$, Caspase-3, Nur-77 and p21 WAFI/CIPI mRNA in HL-60 cells. Cameron et al previously identified a combination of 5-AZaCdR and Trichostatin A (TSA) as producing a synergistic reactivation of $\mathrm{p} 15^{\mathrm{INK} 4 \mathrm{~b}}$ in human leukemic cells $(15)$. We aimed to determine if similar results could be obtained using MG and MCT-3. MG alone significantly increased $\mathrm{p} 15^{\mathrm{INK} 4 \mathrm{~b}}$ and caspase-3 mRNA expression (Fig. 2). The combination 

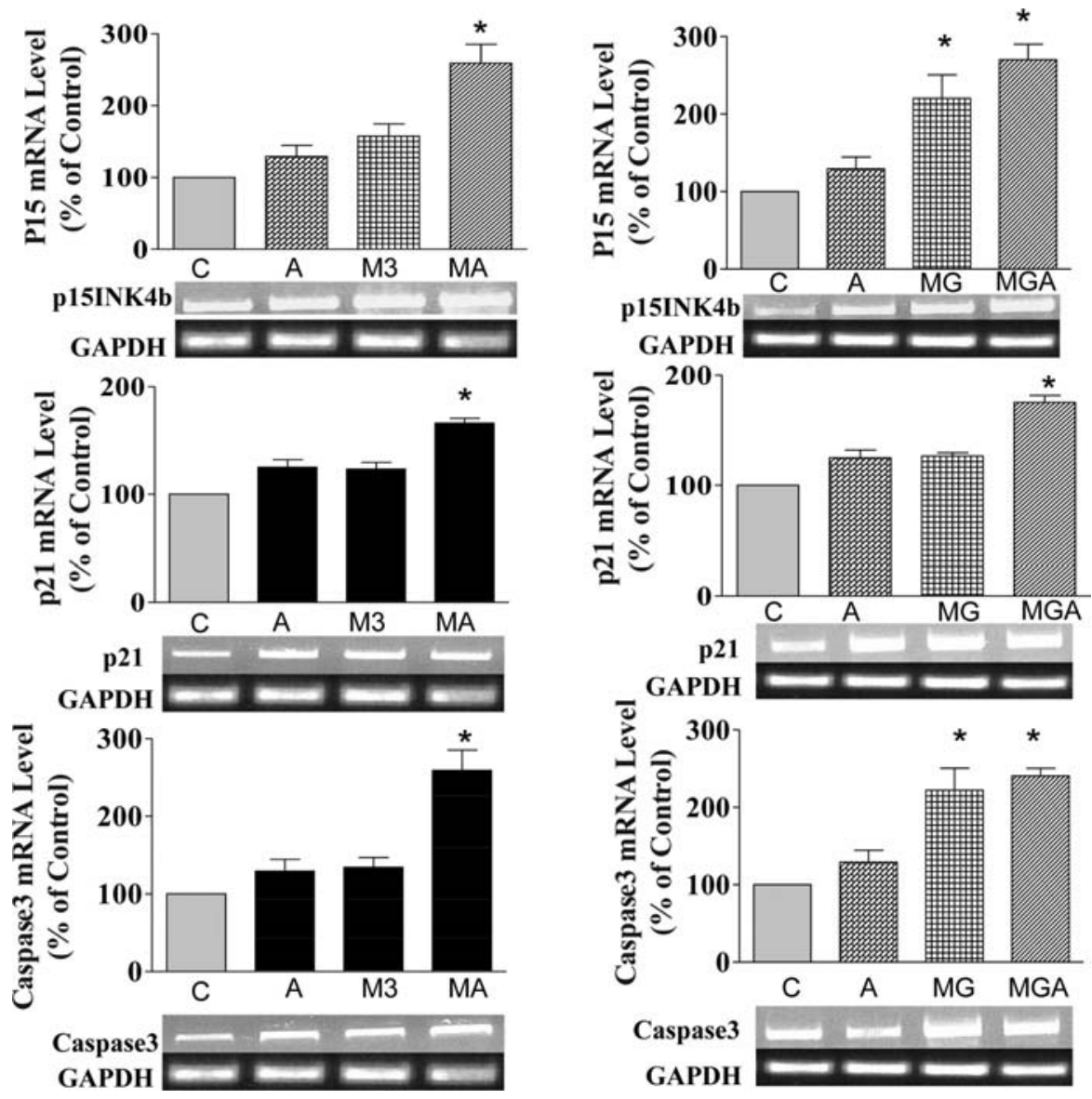

Figure 2. Effect of MG or MCT-3 alone and in combination with AZA on p15I ${ }^{\mathrm{NK} 4 \mathrm{~b}}$, p2 ${ }^{\mathrm{WAF} 1 / \mathrm{CIP} 1}$ and caspase-3 mRNA expression in HL-60 cells. Con, HL-60 cells without treatment; AZA, cells treated with $1.0 \mu \mathrm{M}$ 5-aza-cytidine; M3, cells treated with $0.5 \mu \mathrm{M}$ MCT-3; MA, cells treated with $0.5 \mu \mathrm{M}$ MCT-3 + $1.0 \mu \mathrm{M}$ AZA; MG, cells treated with $0.5 \mu \mathrm{M}$ MGCD0103; MGA, cells treated with $0.5 \mu \mathrm{M}$ MGCD0103+ $1.0 \mu \mathrm{M}$ AZA. ${ }^{*} \mathrm{P}<0.001 \mathrm{vs}$ con, $\mathrm{n}=3$.

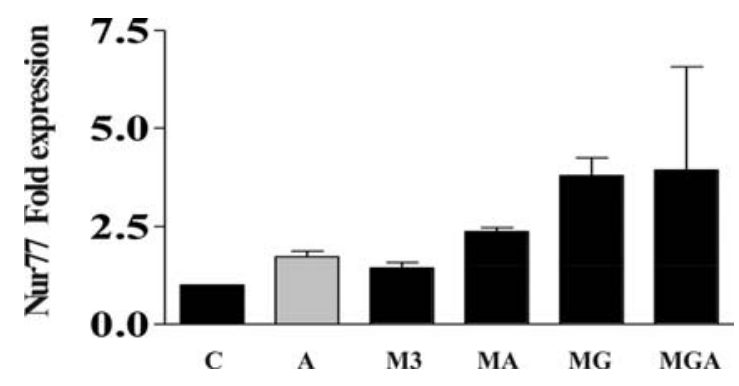

Figure 3. Effect of MG or MCT-3 alone and in combination with AZA on Nur-77 mRNA expression in HL-60 cells. Con, HL-60 cells without treatment; AZA, cells treated with $1.0 \mu \mathrm{M}$ 5-aza-cytidine; M3, cells treated with $0.5 \mu \mathrm{M}$ MCT-3; MA, cells treated with $0.5 \mu \mathrm{M}$ MCT-3 $+1.0 \mu \mathrm{M}$ AZA; MG, cells treated with $0.5 \mu \mathrm{M}$ MGCD0103; MGA, cells treated with $0.5 \mu \mathrm{M}$ MGCD0103+ $1.0 \mu \mathrm{M}$ AZA.

of AZA with either MCT-3 or MG significantly increased p15 ${ }^{\mathrm{INK} 4 \mathrm{~b}}$ (MCT-3 only), p21 and caspase-3 (MCT-3 only) mRNA expression more effectively than either agent alone (Fig. 2).

Real-time PCR analysis demonstrated MG, AZA and MCT-3 increased expression of the novel tumour suppressor gene Nur77 with MG the most potent inducer as a single agent (Fig. 3). The combination of MG and AZA increased Nur77 expression nominally over single agent treatment akin to inhibitory effects on cell growth (Fig. 3).

Effect of MG, MCT-3 and/or AZA on MMP-9 mRNA and proteolytic activity in $H L-60$ cells. AZA mediated induction of MMP-9 expression has been previously reported (24-26) together with HDACi-mediated inhibition of this inductive effect (14). In our system AZA treatment also resulted in a significant increase in MMP-9 mRNA expression and proteolytic activity (Fig. 4). MG and MCT-3 significantly attenuated AZA-induced MMP-9 mRNA expression and proteolytic activity (Fig. 4).

\section{Discussion}

To investigate the anti-leukemic effects and molecular mechanism of action of MG and MCT-3 alone and in combination with AZA we tested the effects of these agents in growth inhibition studies using the HL-60 cell line and on expression of several cell cycle and apoptosis associated genes implicated in the pathogenesis of MDS and AML.

Growth inhibition studies clearly identify MG as the most potent inhibitor of cell growth, of any agent either alone or in combination, with no benefit gained, unlike with MCT-3, 
A

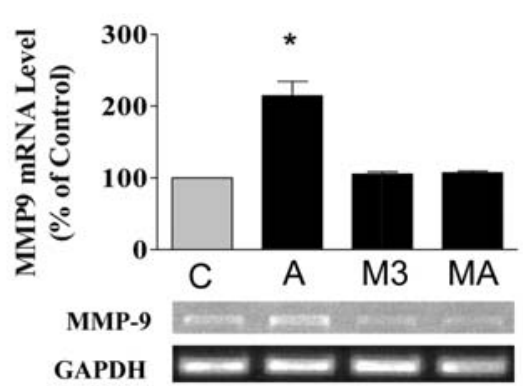

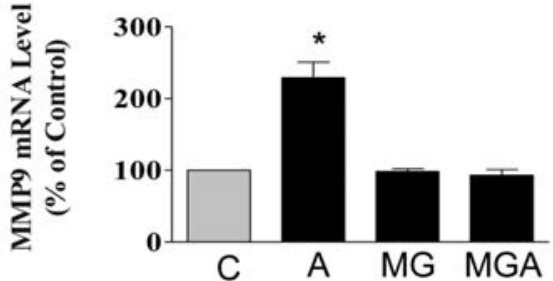

MMP-9

GAPDH

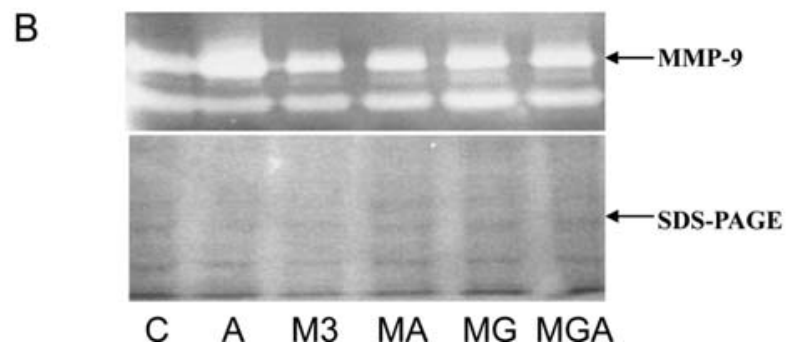

Figure 4. Effect of MG or MCT-3 alone and in combination with AZA on (A) MMP-9 mRNA expression and (B) AZA-induced MMP-9 proteolytic activity in HL-60 cells. Con, HL-60 cells without treatment; AZA, cells treated with 1.0 $\mu \mathrm{M}$ 5-aza-cytidine; M3, cells treated with 0.5 $\mu \mathrm{M}$ MCT-3; MA, cells treated with $0.5 \mu \mathrm{M}$ MCT-3 + 1.0 $\mu \mathrm{M}$ AZA; MG, cells treated with $0.5 \mu \mathrm{M}$ MGCD0103; MGA, cells treated with $0.5 \mu \mathrm{M}$ MGCD0103+ $1.0 \mu \mathrm{M}$ AZA. *P<0.01 AZA vs con, M3, MA, MG, MGA, n=3.

by adding AZA to MG (Fig. 1). Additional studies were performed to gain an understanding of the possible molecular mechanisms responsible for this effect.

The effect of AZA on p15 $5^{\mathrm{INK} 4 \mathrm{~b}}$ expression has been well documented and is thought pivotal in the therapeutic activity of this agent in MDS $(19,27,28)$. Results of our studies demonstrated $\mathrm{p} 15^{\mathrm{INK} 4 \mathrm{~b}}$ expression was, as expected, reactivated by AZA (Fig. 2). Whilst MCT-3 alone increased p15 INK4b expression, consistent with the effects of hydroxamates, short-chain fatty acid and cyclic tetrapeptide HDACi $(6,14,29)$, MG was more potent at induction of $\mathrm{p} 15^{\mathrm{INK} 4 \mathrm{~b}}$. The combination of AZA and MCT-3 resulted in a significant increase in expression of $\mathrm{p} 15^{\mathrm{INK} 4 \mathrm{~b}}$ over single agent treatment although this was not identified when using MG in combination with AZA. MG as a single agent was as potent as all other agents alone or in combination at induction of p15 $5^{\mathrm{INK} 4 \mathrm{~b}}$ (Fig. 2).

It has been suggested that epigenetic silencing of the cyclin-dependent kinase inhibitor $\mathrm{p} 21^{\mathrm{WAF} / \mathrm{CIP} 1}$ is also implicated in the pathogenesis of human cancers (7). We identified a minor increase in $\mathrm{p} 21^{\mathrm{WAF} 1 / \mathrm{CIP} 1}$ expression with AZA or MCT-3 or MG alone, whilst addition of a combination of $\mathrm{MG}$ or MCT-3 to AZA significantly increased expression of p21 ${ }^{\mathrm{WAFl} / \mathrm{CIP} 1}$ over single agent treatment (Fig. 2).

Recent reports suggest demethylating agents and/or HDACi induce apoptosis reliant on activation of the effector caspase-3 (8). Our results concur with these observations and indicate that MG alone was able to significantly induce caspase-3 expression and was the most potent single agent. Whilst MCT-3 as a single agent was less effective than MG at induction of caspase-3 MCT-3 in combination with AZA was more effective than either compound alone at significantly inducing caspase-3 expression (Fig. 2).

Abrogation of the expression of the tumour suppressor gene Nur-77 results in development of acute myeloid leukemia in mice and is a common feature in leukemic blasts from human AML patients (13). We have previously observed up regulation of Nur77 expression by an HDACi alone and in combination with AZA (14). Our observations suggest that MG, AZA and MCT-3 single agent treatment results in an increase in expression of Nur-77 with MG being the more potent agent (Fig. 3). The combination of MCT-3 to AZA treatment slightly increased expression of Nur-77 over single agent treatment (Fig. 3). MG+AZA treatment was no more potent than MG alone which was more potent than any agent alone or in combination. These results identify for the first time induction of Nur77 with a novel benzamide HDACi.

The differences in gene expression profiles for the cell cycle and apoptosis genes examined in response to MG alone or combination with AZA treatment may in part provide a molecular explanation for the observed increase in single agent potency and relative lack of a combined effect of MG and AZA on inhibition of cell growth. The relatively profound induction of p15 ${ }^{\mathrm{INK} 4 \mathrm{~b}}$, caspase-3 and Nur77 expression by MG as a single agent over AZA suggests a significant and potent targeting by MG of these critical cell cycle and apoptosis mediating genes. The lack of effect of the MG+AZA combination over MG alone also suggests that HDACi activity may be of significance in regulating expression of these genes, an effect previously described $(30,31)$.

Our previous results identify attenuation of AZA-induced MMP-9 expression and proteolytic activity by concomitant administration of MCT-1 (14). These observations are now extended to confirm this effect using the novel hydroxamate (MCT-3) and benzamide (MG) HDACi and re-iterate that the anti-leukemia benefit postulated using the combination of AZA and HDACi may also afford protection from potential adverse effects associated with AZA treatment. 
Potency of the effects on cell growth of the novel hydroxamate (MCT-3) and benzamide (MG) HDACi, alone and in combination with AZA, correlate with modulation in expression of genes implicated in cell cycle arrest, apoptosis and the recently identified tumour suppressor Nur77. Interestingly, both classes of HDACi were able to inhibit AZA-mediated induction of MMP-9 expression. These observations suggest that the enhanced anti-leukemia activity of the combination of AZA and HDACi may reside with only certain HDACi classes and may be explained by regulation of genes associated with cell cycle arrest, apoptosis and tumour suppression.

\section{Acknowledgments}

We gratefully acknowledge the support of the Prue Leyden Research Fund in undertaking this work.

\section{References}

1. Balasubramanian S, Verner E and Buggy JJ: Isoform-specific histone deacetylase inhibitors: the next step? Cancer Lett 280: 211-221, 2009

2. Beckers T, Burkhardt C, Wieland H, Gimmnich P, Ciossek T, Maier $\mathrm{T}$ and Sanders K: Distinct pharmacological properties of second generation HDAC inhibitors with the benzamide or hydroxamate head group. Int J Cancer 121: 1138-1148, 2007.

3. Carew JS, Giles FJ and Nawrocki ST: Histone deacetylase inhibitors: mechanisms of cell death and promise in combination cancer therapy. Cancer Lett 269: 7-17, 2008.

4. Dear AE, Mayes P, Liu HB and Perlmutter P: Novel conformational analogues of oxamflatin as histone deacetylase inhibitors. Org Biomol Chem 21: 3778-3784, 2006.

5. Stimson L, Wood V, Khan O, Fotheringham $\mathrm{S}$ and La Thangue NB: HDAC inhibitor-based therapies and haematological malignancy. Ann Oncol 20: 1293-1302, 2009.

6. Hitomi T, Matsuzaki Y, Yokota T, Takaoka Y and Sakai T: p15(INK4b) in HDAC inhibitor-induced growth arrest. FEBS Lett 554: 347-350, 2003.

7. Ocker M and Schneider-Stock R: Histone deacetylase inhibitors:

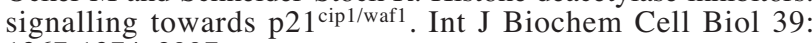
$1367-1374,2007$.

8. Sonnemann J, Hartwig M, Plath A, Saravana Kumar K, Muller C and Beck JF: Histone deacetylase inhibitors require caspase activity to induce apoptosis in lung and prostate carcinoma cells. Cancer Lett 232: 148-160, 2006.

9. Ailenberg M and Silverman M: Trichostatin A-histone deacetylase inhibitor with clinical therapeutic potential-is also a selective and potent inhibitor of gelatinase A expression. Biochem Biophys Res Commun 298: 110-115, 2002.

10. Liu LT, Chang HC, Chiang LC and Hung WC: Histone deacetylase inhibitor up-regulates RECK to inhibit MMP-2 activation and cancer cell invasion. Cancer Res 263: 3069-3072, 2003

11. Jang TH and Sun SH: Alterations in $\mathrm{Ca}^{2+}$ signaling and c-fos and nur77 expression are associated with sodium butyrateinduced differentiation of C6 glioma cell. Chin J Physiol 43: $149-158,2000$

12. Li QX, Ke N, Sundaram R and Wong-Staal F: NR4A1, 2, 3an orphan nuclear hormone receptor family involved in cell apoptosis and carcinogenesis. Histol Histopathol 21: 533-540, 2006.

13. Mullican SE, Zhang S, Konopleva M, Ruvolo V, Andreeff M, Millbrant J and Conneely OM: Abrogation of nuclear receptors $\mathrm{Nr} 4 \mathrm{a} 3$ and Nr4a1 leads to development of acute myeloid leukemia. Nat Med 13: 730-735, 2007.

14. Liu HB, Voso MT, Gumiero D, Duong J, McKendrick JJ and Dear AE: The anti-leukemic effect of a novel histone deacetylase inhibitor MCT-1 and 5-aza-cytidine involves augmentation of Nur77 and inhibition of MMP-9 expression. Int J Oncol 34: 573-579, 2009

15. Cameron EE, Bachman KE, Myohanen S, Herman JG and Baylin SB: Synergy of demethylation and histone deacetylase inhibition in the re-expression of genes silenced in cancer. Nat Genet 21: 103-107, 1999.
16. Lemaire M, Momparler LF, Farinha NJ, Bernstein M and Momparler RL: Enhancement of antineoplastic action of 5-aza2'-deoxycytidine by phenylbutyrate on L1210 leukemic cells. Leuk Lymphoma 45: 147, 2004.

17. Shaker S, Bernstein M, Momparler LF and Momparler RL: Preclinical evaluation of antineoplastic activity of inhibitors of DNA methylation (5-aza-2'-deoxycytidine) and histone deacetylation (trichostatin A, depsipeptide) in combination against myeloid leukemic cells. Leuk Res 27: 437-444, 2003.

18. Yang H, Hoshino K, Sanchez-Gonzalez B, Kantarjian H and Garcia-Manero G: Antileukemia activity of the combination of 5-aza-2'-deoxycytidine with valproic acid. Leuk Res 29: 739-748, 2005.

19. Gore SD, Baylin S, Sugar E, Carraway H, Miller CB, Carducci M, Grever M, Galm O, Dauses T, Karp JE, Rudek MA, Zhao M, Smith BD, Manning J, Jiemjit A, Dover G, Mays A, Zwiebel J, Murgo A, Weng LJ and Herman JG: Combined DNA methyltransferase and histone deacetylase inhibition in the treatment of myeloid neoplasms. Cancer Res 66: 6361-6369, 2006.

20. Soriano AO, Yang H, Faderl S, Estrov Z, Giles F, Ravandi F, Cortes J, Wierda WG, Ouzounian S, Quezada A, Pierce S, Estey EH, Issa JP, Kantarjian HM and Garcia-Manero G: Safety and clinical activity of the combination of 5-azacytidine, valproic acid, and all-trans retinoic acid in acute myeloid leukemia and myelodysplastic syndrome. Blood 110: 2302-2308, 2007.

21. Fournel M, Bonfils C, Hou Y, Yan PT, Trachy-Bourget MC, Kalita A, Liu J, Lu AH, Zhou NZ, Robert MF, Gillespie J, Wang JJ, Ste-Croix H, Rahil J, Lefebvre S, Moradei O, Delorme D, Macleod AR, Besterman JM and Li Z: MGCD0103, a novel isotype-selective histone deacetylase inhibitor, has broad spectrum antitumor activity in vitro and in vivo. Mol Cancer Ther 7: 759-768, 2008.

22. Garcia-Manero G, Assouline S, Cortes J, Estrov Z, Kantarjian H, Yang H, Newsome WM, Miller WH Jr, Rousseau C, Kalita A, Bonfils C, Dubay M, Patterson TA, Li Z, Besterman JM, Reid G, Laille E, Martell RE and Minden M: Phase 1 study of the oral isotype specific histone deacetylase inhibitor MGCD0103 in leukemia. Blood 112: 981-989, 2008.

23. Kim YB, Lee KH, Sugita K, Yoshida M and Horinouchi S: Oxamflatin is a novel anti-tumor compound that inhibits mammalian histone deacetylase. Oncogene 18: 2461-2470, 1999.

24. Sato N, Maehara N, Su GH and Goggins M: Effects of 5-aza-2'deoxycytidine on matrix metalloproteinase expression and pancreatic cancer cell invasiveness. J Natl Cancer Inst 95: 327-330, 2003.

25. Chicoine E, Esteve PO, Robledo O, van Themsche C, Potworowski EF and St-Pierre Y: Evidence for the role of promoter methylation in the regulation of MMP-9 gene expression. Biochem Biophys Res Commun 97: 765-772, 2002.

26. Couillard J, Demers M, Lavoie G and St-Pierre Y: The role of DNA hypomethylation in the control of stromelysin gene expression. Biochem Biophys Res Commun 342: 1233-1239, 2006.

27. Uchida T, Kinoshita T, Nagai H, Nakahara Y, Saito H, Hotta T and Murate T: Hypermethylation of the $\mathrm{p} 15^{\mathrm{INK} 4 \mathrm{~B}}$ gene in myelodysplastic syndromes. Blood 90: 1403-1409, 1997.

28. Daskalakis M, Nguyen TT, Nguyen C, Guldberg P, Kohler G and Wijermans P: Demethylation of a hypermethylated $\mathrm{P} 15 / \mathrm{INK} 4 \mathrm{~B}$ gene in patients with myelodysplastic syndrome by 5-aza-2'-deoxycytidine [decitabine] treatment. Blood 100: 2957-2964, 2002

29. Odenike OM, Alkan S, Sher D, Godwin JE, Huo D, Brandt SJ, Green M, Xie J, Zhang Y, Vesole DH, Stiff P, Wright J, Larson RA and Stock W: Histone deacetylase inhibitor romidepsin has differential activity in core binding factor acute myeloid leukemia. Clin Cancer Res 14: 7095-7101, 2008.

30. Hitomi T, Matsuzaki Y, Yasuda S, Kawanaka M, Yogosawa S, Koyama M and Tantin D and Sakai T: Oct-1 is involved in the transcriptional repression of the p15(INK4b) gene. FEBS Lett 581: 1087-192, 2007

31. Wallace DM, Donovan M and Cotter TG: Histone deacetylase activity regulates apaf- 1 and caspase- 3 expression in the developing mouse retina. Invest Ophthalmol Vis Sci 47: 2765-2772, 2006. 